\title{
Experimental Hybridization between Toads from Kyoto and Toads from Miyako Is. and France
}

\author{
Massfumi Matsui \\ (Biological Laboratory, Yoshida College, Kyoto University)
}

\begin{abstract}
Intersubspecific hybridizations among common toads were made, and the morphological characters of the hybrids thus obtained were examined. Females of Bufo bufo iaponicus from Momoyama, Kyoto were crossed experimentally with males of $B$. b. miyakonis from Miyako Is., Ryukyu Archipelago and a male of $B$. b. spinosus from Banyuls, Southern France. Early development of hybrid embryos proceeded in the same normal way as the control embryos, although the percentages of normally cleft eggs were slightly lower in the former than in the latter. Most of the normally cleft hybrid eggs became normal swimming tadpoles and attained the completion of metamorphosis. The japonicus o $\times$ miyakonis $\hat{o}$ hybrid tadpoles had longer tails than the control, while the hybrid japonicus o $\times$ spinosus of tadpoles had the smallest tails. Immediately after metamorphosis, the hybrid young toads had shorter hindlegs than the controls and the older young hybrids of two to four months after metamorphosis differed markedly from the controls in this respect. Some of the male hybrids of japonicus $\$ \times$ miyakonis $\hat{o}$ attained sexual maturity in the fall. Histological examinations of the young toads revealed that both male and female gonads of japonicus i $\times$ miyakonis $\hat{o}$ were developing normally, whereas no normal spermatogonia were developing in the testes and the ovarian structures were completely destroyed in the japonicus o $\times$ spinosus 0 hybrids. These results seem to indicate that the genetical isolation is somewhat advanced between Japanese japonicus and French spinosus, and that they could be treated as two distinct species.
\end{abstract}

\section{INTRODUCTION}

The common Toad, Bufo bufc, and its allies are distributed widely from northwest Africa through most of the Eurasian Continent with Japan their easternmost limit. Though extensive descriptive studies have been made on this toad group in the past years, there still remain many unsolved questions as to the status and relation of not a few known forms. In particular, as to the relation between Asian and European common

Japanese Journal of Herpetology 6 (3) :80-92. 1976. 
toads, our knowledge is still almost at the same stage as in Stejneger's era (Stejneger, 1907 ; Matsui, 1974a, 1975a, 1976). There have been increasing studies on the systematics of Anurans in which the results of the cross experiments, together with other morphological and non-morphological characters, play a great role in determining the taxonomic relation of one form to another. This kind of experimental study on the genus Bufo was initiated by A. P. Blair, (1941) on the North American toad species, and recently W. F. Blair and his co-workers have compiled a vast amount of data on this genus (Blair, 1972). Even in this context, the knowledge of Eurasian toads, compared with those of America, is far from complete. With regards to Japanese anurans, studies of hybridization have been made by several authors (Daito, 1968; Kawamura, 1942-1960; Kuramoto, 1967, 1974; Moriya, 1951, 1960). Most of their studies, however, are confined to true frogs (chiefly of the genus Rana), and actualiy no study on toads has been made in Japan so far. Taking all these circumstances into consideration, the author is undertaking hybridization experiments among the known forms of Eurasian common toads. The results of the hybridization experiments between toads of Kyoto and those of Miyako Is., and Southern France are reported in this article.

\section{MATERIALS AND METHODS}

For crossing experiments among three subspecies of common toads, 7 females and 2 males of Bufo bufo japonicus SCHLEGEL from Momoyama, Kyoto, 3 males of B. b. miyakonis OKADA from Miyako Is., Ryukyu Archipelago and one male of B. b. spinosus DAUDIN from Banyuls, Southern France were used.

The laboratory hybridizations were performed during the breeding season of japonicus at Momoyama, March in 1974 and 1975. Male toads from Miyako Is. and Banyuls had been reared for 2 months before crossing, and were induced to clasp by Gonadotrophin injection (150 IU $\times 2$ times for each animal). Immediately after being collected at the breeding pond, the japonicus females were carried to the laboratory for crossing. The eggs of japonicus females were fertilized not artificially (Rugh, 1934) but by the natural process. The eggs were inseminated by the male (during amplexus) as they emerged from the cloaca of the female. No difficulty was encountered in inducing males of miyakonis and spinosus to clasp females of japonicus.

The procedures employed in rearing the embryos were essentially similar to those used in other work of this type (Blair, 1955 ; Volpe, 1956). The egg strings from each fertilization were cut into small groups. Approximately 50 eggs were placed in a tank containing $2000 \mathrm{cc}$ of water and were raised at $13^{\circ} \mathrm{C}-21^{\circ} \mathrm{C}$ (Mean $14.6^{\circ} \mathrm{C}$ ). Tadpoles were fed boiled spinach. The water was changed every day and the dead embryos were removed. Thus, all kinds of tadpoles were reared under like conditions. Juvenile toads were fed fruit flies (Drosophila spp.), termites (Reticulitermes speratus) and meal-worm larvae (Tenebrio molitor). Some individuals were marked by the ordinary toe clipping 
methods and released on the campus of the Zoological Institute of Kyoto University. Most of these toads were recaptured in two to four months. The developmental stages of tadpoles were determined following the table of Limbaugh and Volpe (1957). All the sample specimens were fixed in $10 \%$ formalin and stored in $70 \%$ ethanol. Measurements to the nearest $0.05 \mathrm{~mm}$ were made with dial calipers and under a binocular dissecting microscope equipped with an occular micrometer. The gonads of young and some matured toads were fixed in Bouin's fluid or $10 \%$ formalin, sectioned by the ordinary paraffin method ranging 5 to $8 \mu$ in thickness and stained with haematoxylin and eosine.

\section{OBSERVATIONS}

I. Production of hybrid embryos

The results of the crossing experiments are shown in Table 1 . Though the lack of

Table 1. Results of hybridization experiments

\begin{tabular}{|c|c|c|c|c|c|}
\hline female ${ }^{\text {Crosses* }}$ male & $\begin{array}{l}\text { No. } \\
\text { eggs }\end{array}$ & $\begin{array}{l}\text { No. cleft } \\
\text { eggs }(\%)^{* *}\end{array}$ & $\begin{array}{l}\text { No. Hatched } \\
(\%)^{* *}\end{array}$ & $\begin{array}{l}\text { No. normal } \\
\text { tadpoles }(\%)^{* *}\end{array}$ & $\begin{array}{l}\text { No. metamor } \\
\text { phosed }(\%)\end{array}$ \\
\hline$j a p \$ 751 \times j a p \$ 758$ & 123 & $123(100)$ & $123(100)$ & $109(88.6)$ & \multirow{2}{*}{$74 / 75(98.7)$} \\
\hline jap $\$ 752 \times$ jap $\$ 759$ & 127 & $126(99.2)$ & $126(100)$ & $115(91.3)$ & \\
\hline jap $\$ 741 \times$ miy $\$ 741$ & 252 & $236(93.7)$ & - & - & - \\
\hline jap $\$ 753 \times$ miy $\$ 751$ & 500 & $493(98.6)$ & $489(99.2)$ & $448(91.6)$ & \multirow{2}{*}{$74 / 75(98.7)$} \\
\hline jap $\$ 754 \times$ miy $\$ 752$ & 508 & $345(67.9)$ & $328(95.1)$ & $268(81.7)$ & \\
\hline jap $\$ 756 \times s p i \quad \$ 751$ & 481 & $49(10.2)$ & $35(71.4)$ & 1 (2.9) & $0(0)$ \\
\hline jap $\$ 757 \times$ spi $\$ 751$ & 718 & $702(97.8)$ & $632(90.0)$ & $618(97.8)$ & $75 / 75(100)$ \\
\hline
\end{tabular}

* jap, miy and spi are abbreviations for Bufo bufo japonicus, B. b. miyakonis and B. b. spinosus respectively.

** With the number given in the preceding column being 100 .

gravid females of miyakonis and spinosus prevented operating intrasubspecific control experiments of these two forms, the males of both subspecies were considered to be potent, since 68 to 99 percent of eggs inseminated by these males cleaved normally in the crossing experiments between japonicus females. In all the three series of japonicus females mated with miyakonis males, percentages of normally cleft eggs were slightly lower than in the control series; 68 to 99 percent of eggs in the experiment series cleaved normally in contrast with 99 to 100 percent in the control. Most of the nomally cleft eggs became normal swimming larvae in the experimental series as in the control. There was no marked difference in the growth rate between these hybrids and controls.

In one of the two experimental crosses between japonicus females and the spinosus male, only 10 percent of eggs cleaved normally. This might be due not to the defect of spinosus sperm but to the bad physiological condition of japonicus female $\$ 756$, since in the other series, 98 percent of the eggs, also inseminated by the same spinosus male, cleaved normally, which value is almost the same as that in the control series. Moreover, 
the shape of the eggs oviposited in the former case was abnormally triangular, which fact strongly suggested poor fertilizability of the eggs. The small number of cleaved eggs became abnormal swimming larvae, none of which reached metamorphic stages. On the contrary, in the latter experimental series of female japonicus $\$ 757$ with the same spinosus, most of the eggs cleaved normally and became quite normal swimming larvae. They grew almost at the same pace as the controls, and the metamorphosis took place about 50 days after insemination.

II. External characters of hybrid tadpoles

The body color of hybrid tadpoles, both jap. $+\times$ miy. $\hat{o}$ and jap. $+\times \times s p i$. $\hat{o}$, was almost identical with that of the control, but there were some differences in the body shape of each tadpole. As the body shape of tadpoles changes with the growth, the comparisons were made with individuals of the same stages of development. The dimensions of each body part are shown in Tables 2 and 3, 25 days and 35 days after insemination, respectively.

Table 2. Measurements (mean and one standard deviation, in $\mathrm{mm}$ ) of the hybrids and controls of the toad tadpoles, 25 days after insemination.

\begin{tabular}{|c|c|c|c|}
\hline Parents & $j a p \& \times j a p \hat{o}$ & $j a p \circ \times$ miy & $j a p$ o $\times s p i$ \\
\hline Sample size & 11 & 17 & 10 \\
\hline Devel. Stage & $30-31$ & $30-31$ & $30-31$ \\
\hline Snout-Vent length & $9.06 \pm 0.69$ & $9.43 \pm 0.60$ & $9.54 \pm 0.56$ \\
\hline Body depth & $4.66 \pm 0.51$ & $4.83 \pm 0.40$ & $5.09 \pm 0.58$ \\
\hline Body breadth & $5.47 \pm 0.59$ & $5.66 \pm 0.40$ & $5.94 \pm 0.62$ \\
\hline Tail length & $15.11 \pm 1.42$ & $15.96 \pm 0.77$ & $14.37 \pm 0.70$ \\
\hline Tail depth & $4.71 \pm 0.43$ & $4.74 \pm 0.33$ & $4.54 \pm 0.47$ \\
\hline Tail breadth & $1.39 \pm 0.20$ & $1.44 \pm 0.19$ & $1.57 \pm 0.12$ \\
\hline Depth of muscular portion & $1.97 \pm 0.21$ & $1.96 \pm 0.15$ & $1.80 \pm 0.10$ \\
\hline Hind-limb length & $1.03 \pm 0.17$ & $0.99 \pm 0.13$ & $0.99 \pm 0.11$ \\
\hline Snout to spiracle & $6.06 \pm 0.43$ & $6.24 \pm 0.44$ & $6.35 \pm 0.44$ \\
\hline Oral disc breadth & $2.46 \pm 0.20$ & $2.34 \pm 0.16$ & $2.56 \pm 0.22$ \\
\hline Interorbital space & $2.48 \pm 0.18$ & $2.68 \pm 0.16$ & $2.68 \pm 0.16$ \\
\hline$\frac{\text { Tail length }}{\text { Snout-Vent length }} \times 100$ & $166.61 \pm 6.55$ & $169.62 \pm 8.47$ & $151.02 \pm 10.05$ \\
\hline
\end{tabular}

In the 25-day tadpoles (stages 30-31), there were no statistically significant differences in the snout-vent length (S-VL) of the three groups, although there was a tendency for the hybrids jap. $\& \times$ miy. $\hat{o}$ to be larger than those jap. $+\times s p i$. $\hat{\delta}$, which were in turn larger than the control tadpoles of jap. $ᄋ \times j a p$. $\hat{\delta}$. The most remarkable difference was the relative length of the tail. In the jap. $+\times$ miy. $\delta$ hybrids, the tail was long and the tail fins were low, compared with the control tadpoles. On the contrary, the jap. 우 $\times s p i$. $\hat{o}$ hybrids had shorter tails than the controls. Thus, the hybrid tadpoles of jap. ㅇ $\times$ 
miy. o could easily be discriminated by their long tails (169.6\% of the S-VL) from the short-tailed $(151.0 \%$ of S-VL) jap. $+\times s p i$. 0 hybrids. Furthermore, the ratio of the tail depth to the body depth was the smallesi in the jap. 우 $\times s p$. of hybrids, indicating poor tail development in that group. The body shape of the hybrids jap. $+\times>s p i$. 0 somewhat differed from that of the other two groups: the body of the former was broader and higher than that of the latter. In the hybrids jap. $ᄋ \times$ miy. $\hat{\delta}$, the mouth parts were

Table 3. Measurements (mean and one standard deviation, in $\mathrm{mm}$ ) of the hybrids and controls of the toad tadpoles, 35 days after insemination.

\begin{tabular}{lccc}
\multicolumn{1}{c}{ Parents } & jap o $\times$ jap $\hat{o}$ & jap o $\times$ miy $\hat{o}$ & jap o $\times s p i \hat{o}$ \\
\hline Sample size & 10 & 16 & 10 \\
Devel. Stage & $33-36$ & $34-36$ & $34-36$ \\
Snout-Vent length & $11.42 \pm 1.13$ & $11.44 \pm 0.58$ & $11.39 \pm 0.60$ \\
Body depth & $5.57 \pm 0.54$ & $5.12 \pm 0.39$ & $5.42 \pm 0.56$ \\
Body breadth & $6.80 \pm 0.80$ & $6.70 \pm 0.42$ & $7.01 \pm 0.57$ \\
Tail length & $18.56 \pm 1.98$ & $19.53 \pm 1.60$ & $17.91 \pm 0.89$ \\
Tail depth & $5.61 \pm 0.58$ & $5.77 \pm 0.43$ & $5.46 \pm 0.41$ \\
Tail breadth & $2.12 \pm 0.27$ & $2.12 \pm 0.15$ & $2.06 \pm 0.17$ \\
Depth of muscular portion & $2.43 \pm 0.29$ & $2.59 \pm 0.17$ & $2.35 \pm 0.11$ \\
Hind-limb length & $2.32 \pm 0.59$ & $2.64 \pm 0.54$ & $2.25 \pm 0.44$ \\
Snout to spiracle & $7.57 \pm 0.82$ & $7.48 \pm 0.42$ & $7.58 \pm 0.51$ \\
Oral disc breadth & $3.18 \pm 0.30$ & $2.88 \pm 0.18$ & $2.95 \pm 0.27$ \\
Interorbital space & $3.27 \pm 0.25$ & $3.21 \pm 0.18$ & $3.25 \pm 0.22$ \\
$\quad$ Tail length & $162.69 \pm 8.52$ & $170.59 \pm 10.51$ & $157.38 \pm 6.71$ \\
\hline Snout-Vent length & & & \\
\hline
\end{tabular}

relatively smaller than those of the other two groups. These tendencies, characteristics of 25-day tadpoles, held true in the older tadpoles of 35 days after insemination (stages 33 -36). There was no marked difference in the body length of the 35-day tadpoles of the three groups. Hybrids jap. 우 $\times$ miy. ô had longer tails, lower bodies and smaller mouth parts than the jap. . $\times$ spi. of hybrids and controls. The relative tail length was smaller (157. 4\% of S-VL) in the jap. o $\times$ spi. o hybrids (162.7\% in the controls and $170.6 \%$ in the jap. o $\times$ miy. of hybrids).

III. External characters of hybrid toads

Hybrid young toads, jap. $+\times \times$ miy. $\hat{0}$, immediately after metamorphosis, tended to be larger (S-VL $11.2 \mathrm{~mm}$ ) than the controls $(10.4 \mathrm{~mm})$, but the individual variations within each group was great and the difference was not statistically significant. Jap. $ᄋ \times$ miy. 0 hybrids had slightly smaller heads than the other two groups as shown by the relative values (in terms of 100th of S-VL) of head width and eye margin distance.

The most remarkable difference in the body proportion of the three groups was seen in the length of the hind-leg (Table 4). Since the exact measurements of the total 
Table 4. Measurements (Mean and one Standard Deviation, in $\mathrm{mm}$ ) of the hybrid and normal toads immediately after metamorphosis.

\begin{tabular}{|c|c|c|c|}
\hline Parents & $j a p$ 우 $\times j a p$ o & $j a p+\circ \times$ miy $\delta$ & $j a p+\& \times s p i$ \\
\hline Sample size & 11 & 10 & 10 \\
\hline Snout-Vent length & $10.4 \pm 0.7$ & $11.2 \pm 0.6$ & $10.6 \pm 0.6$ \\
\hline Head width & $4.4 \pm 0.3$ & $4.4 \pm 0.2$ & $4.5 \pm 0.3$ \\
\hline $\begin{array}{l}\text { Distance between outer } \\
\text { margins of upper eyelids }\end{array}$ & $4.1 \pm 0.2$ & $4.2 \pm 0.3$ & $4.1 \pm 0.2$ \\
\hline Tibia length & $4.0 \pm 0.3$ & $3.9 \pm 0.4$ & $3.7 \pm 0.2$ \\
\hline
\end{tabular}

length of the hind-leg were difficult to make on the fixed young toads, the greatest length of the tibia was taken. The relative lengths of the tibia were similar in the jap. o $\times$ miy. $\hat{o}$ and jap. o $\times$ spi. 0 hybrids ( $34.5 \%$ and $34.9 \%$, respectively), but they were slightly smaller than that of the controls (38.9\%). As is evident from these values, the hybrids had shorter legs than the controls. Control young toads, jap. $q \times j a p$. $\hat{\delta}$, were wholly black at the time of metamorphosis. The back became coppery in a few days and the black color of the belly became paler. The young toads about a month after metamorphosis were coppery on the back with two rows of chevron-shaped bands. The back of the thigh and the tibia was mottled with dark bars. The number and degree of these bands varied individually. Dark stripes on the flank became clearer and the belly was dirty gray with many dark speckles. Hybrids, jap. 우 $\times$ miy. $\hat{o}$ and jap. + $\times s p i$. $\hat{\delta}$, were almost the same in their coloration as the controls. In the jap. $+\times s p i$. $\hat{o}$ young, the back was more brilliantly coppery and the bars on the hind-legs were more sharply marked than in the controls. Moreover, the belly of these toads was light gray with less dark speckles than in the control.

The growth rate varied remarkably among individuals, and the young toads about four months after metamorphosis were about 35 to $60 \mathrm{~mm}$ in S-VL (Fig.1). Hybrids, especially $j a p .+\times$ miy. $q$, tended to grow more rapidly than the controls. In contrast to the metamorphosed stages, half-grown toads of three to four months were morphologically well differentiated. The toads of the three groups were distinguished from each other both in the body proportions and in the coloration. As the body proportions change with growth in anurans, it is undesirable simply to compare ratios of each part of the body against S-VL. Each individual here treated, however, belongs to immature stages of less than one year (except some jap. 우 $\times$ miy. 1 hybrids). Thus, the comparison of body proportions were made on the basis of percentage ratios of each measurement against S-VL (Table 5). The smallness of the sample size limited generalized conclusions, but as is evident from the Table 5, the two hybrid groups had similar proportions and were slightly different from the controls in several dimensions. Hybrids had shorter extremities than the controls. Parotoid glands of $j a p$. $9 \times$ spi. o hybrids were shorter and broader than those of jap. $\$ \times$ miy. $\hat{o}$ hybrids and the controls. The number and the develop- 


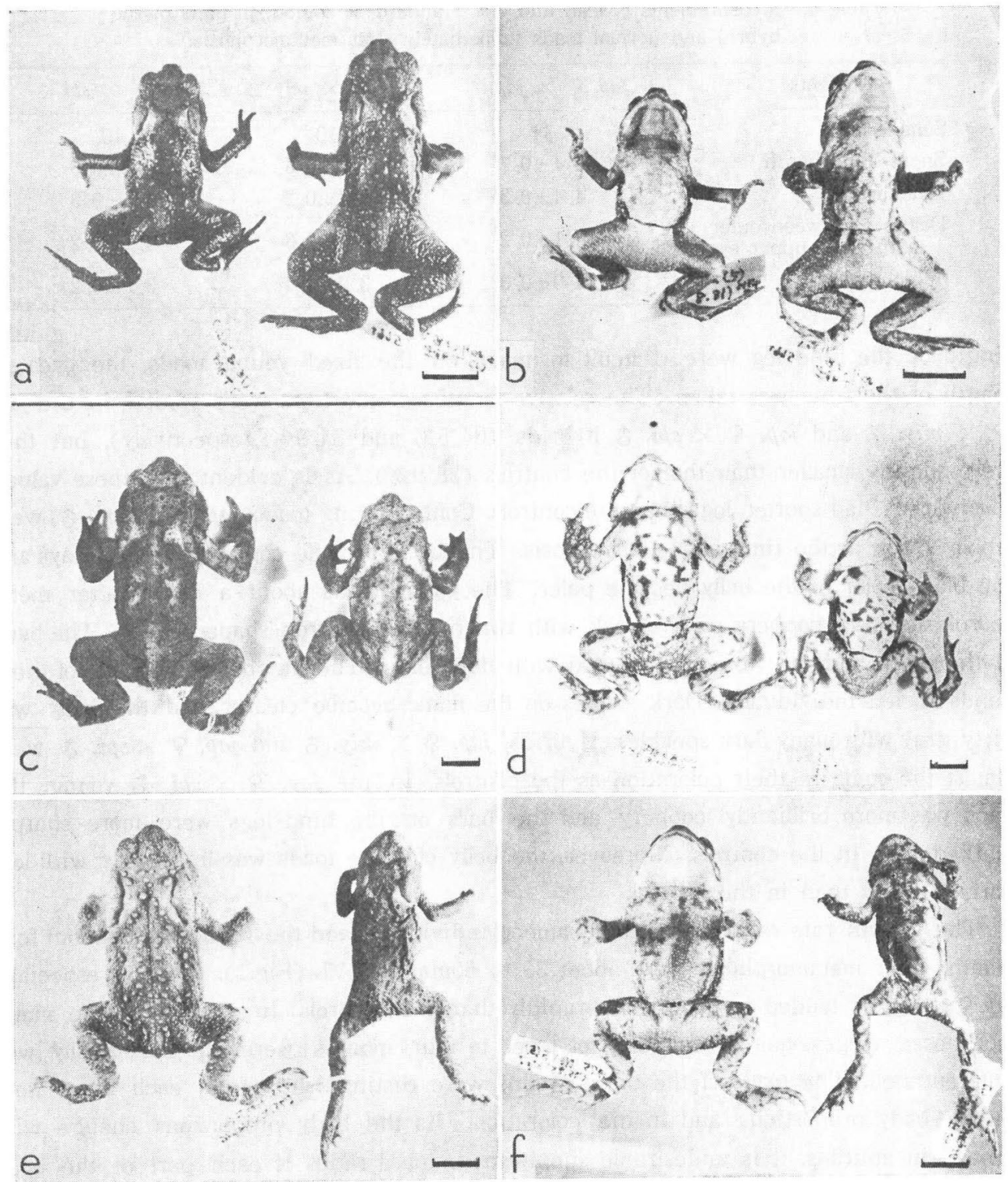

Fig. 1. Dorsal (left rows) and ventral (right) views of young toads three to four months after metamorphosis. In each figure, the female is on the left side and the male on the right. The Black lines are scales of $10 \mathrm{~mm}$. a, b. Controls, japonicus of $\times$ japonicus $\hat{o} ;$ c, d. Hybrids, japonicus of $\times$ miyakonis $\hat{o} ; \mathrm{e}, \mathrm{f}$. Hybrids, japonicus 次pinosus $\hat{o}$.

mental conditions of dorsal warts and coarse ventral granules were more remarkable in the hybrids than in the controls. Further, the top of the warts was more sharply spiny, and the webs of the hind feet were more developed and their edges more sharply den- 
Tabie 5. Measurements of young toads, three to four months after metamorphosis. Snoutvent lengths ( $\mathrm{S}-\mathrm{VL}$ ) are actual values (in $\mathrm{mm}$ ) with means followed by extremes in parenthesis, and all other dimensions are represented by relative values with means and one standard errors. Abbreviations: PL (Parotoid Length), PW (Parotoid Width), DT (Diameter of Tympanum), ET (Eye to Tympanum), FLL (Fore-Leg Length), HLL (Hind-Leg Length), FL (Foot Length), TL (Tibia Length).

\begin{tabular}{|c|c|c|c|c|c|c|}
\hline $\begin{array}{l}\text { Combination } \\
\text { Sex } \\
\text { Sample size }\end{array}$ & 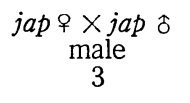 & $\begin{array}{c}j a p \text { ㅇ } \times \text { miy } \\
\text { male } \\
5\end{array}$ & $\begin{array}{c}j a p \text { 우 } \times s p i \times \\
\text { male } \\
1\end{array}$ & $\begin{array}{c}j a p \text { o } \times j a p \delta \\
\text { female } \\
1\end{array}$ & $\begin{array}{c}j a p \text { o } \times \text { miy } \\
\text { female } \\
5\end{array}$ & $\begin{array}{c}j a p \text { o } \times s p i \text { o } \\
\text { female } \\
2\end{array}$ \\
\hline S-VL & 41.0 & 37.9 & 39.2 & 33.2 & 47.1 & 46.0 \\
\hline (Range) & $(37.6-45.8)$ & $(27.0-53.5)$ & - & - & $(42.2-62.5)$ & $(40.2-51.7)$ \\
\hline $\mathrm{PL} / \mathrm{PW}$ & $3.2 \pm 0.2$ & $3.0 \pm 0.2$ & 2.6 & 3.0 & $3.0 \pm 0.2$ & 2.6 \\
\hline $\mathrm{DT} / \mathrm{ET}$ & $1.3 \pm 0.1$ & $1.5 \pm 0.1$ & 1.3 & 2.0 & $1.5 \pm 0.1$ & 1.7 \\
\hline FLL/S-VL $\times 100$ & $67.8 \pm 0.2$ & $60.7 \pm 1.8$ & 60.7 & 69.0 & $59.9 \pm 0.9$ & 62.4 \\
\hline $\mathrm{HLL} / \mathrm{S}-\mathrm{VL} \times 100$ & $126.2 \pm 0.8$ & $113.5 \pm 2.2$ & 113.3 & 128.0 & $113.9 \pm 1.5$ & 115.5 \\
\hline FL/S-VL $\times 100$ & $40.9 \pm 0.3$ & $36.6 \pm 0.7$ & 35.2 & 39.8 & $37.5 \pm 0.7$ & 38.2 \\
\hline $\mathrm{TL} / \mathrm{S}-\mathrm{VL} \times 100$ & $37.3 \pm 0.3$ & $32.2 \pm 0.6$ & 32.1 & 37.4 & $33.2 \pm 0.2$ & 33.9 \\
\hline
\end{tabular}

ticulate in the hybrids. In contrast to the metamorphosed stages, young toads of four months varied individually in their coloration. The back of the controls was pinkish brown and the black horny layer on the wart poorly developed. The jap. $\$ \times$ miy. 0 hybrids were orangish brown on the back with chevron-shaped orange markings behind the parotoids and on the sacral regions. The top of the warts was surmounted with a black spine. There were dark bands on the surface of the extremities. The belly was dirty yellowish white, with several dark spots, which varied among individuals in number and distinctness. Broad dark stripes extended posteriorly on the flank from behind the parotoid glands. The jap. + $\times s p i$. o hybrids were similar to jap. $+\times$ miy. 0 hybrids and were somewhat different from the controls. For the sake of comparison, characters of the parental populations, japonicus from Momoyama, miyakonis from Miyako Is. and spinosus from Banyuls are also shown in Table 6. As there were few individuals of jap.

Table 6. Measurements of adult toads. Snout-vent lengths are actual mean values (in $\mathrm{mm}$ ), and all other dimensions are represented by relative mean values. Abbreviations are the same as those used in the Table 5 .

\begin{tabular}{lcccccc}
\hline $\begin{array}{c}\text { Subspecies } \\
\text { Sex } \\
\text { Sample size }\end{array}$ & $\begin{array}{c}\text { japonicus } \\
\text { male } \\
23\end{array}$ & $\begin{array}{c}\text { miyakonis } \\
\text { male } \\
13\end{array}$ & $\begin{array}{c}\text { spinosus } \\
\text { male } \\
1\end{array}$ & $\begin{array}{c}\text { japonicus } \\
\text { female } \\
20\end{array}$ & $\begin{array}{c}\text { miyakonis } \\
\text { female } \\
37\end{array}$ & $\begin{array}{c}\text { spinosus } \\
\text { female } \\
1\end{array}$ \\
\hline S-VL & 99.4 & 72.1 & 31.5 & 108.9 & 86.7 & 99.2 \\
PL/PW & 3.0 & 2.7 & 2.2 & 3.0 & 2.6 & 2.5 \\
DT/ET & 1.2 & 1.5 & 1.9 & 1.2 & 1.4 & 1.7 \\
FLL/S-VL $\times 100$ & 66.2 & 60.3 & 67.5 & 64.4 & 56.1 & 63.0 \\
HLL/S-VL $\times 100$ & 134.4 & 121.5 & 136.4 & 124.0 & 114.5 & 128.2 \\
FL/S-VL $\times 100$ & 45.9 & 39.6 & 46.4 & 40.4 & 36.7 & 42.5 \\
TL/S-VL $\times 100$ & 38.0 & 34.6 & 39.0 & 36.1 & 33.3 & 36.1 \\
\hline
\end{tabular}


$9 \times j a p . \hat{o}$ controls and jap. $\$ \times$ spi. 0 hybrids, and further, the parental spinosus were but one male and one female, it was impossible to generalize the results of the observations. It was clear, however, that some characters of the hybrids were maternal, and some others paternal, while the remaining ones were intermediate between both parents. The relative length of the extremities, showing marked differences among young toads, is the characther which discriminates adult miyakonis from japonicus, and the jap. $+\times$ miy. hybrids resembled their paternal population in this character. There was no difference in the relative length of extremities between the adult male population of japonicus and spinosus, but this might be due to the fact that only one spinssus was used for the present crossing. Therefore, which parental source affected the hybrids in this character is unknown. By contrast, the wide black bands on the flanks and the dirty markings on the belly of the hybrids, though their degree varied among individuals, were doubtless from their maternal source.

IV. Structure of gonads

Some of jap. o $\times$ miy. o hybrids reached sexual maturity, having well-developed nuptial asperities, and uttered cries when handled. The structures of the gonads of the hydrids and controls were as follows.

A control male, jap. ㅇ $\times$ jap. $\hat{o}$ (Fig. $2 \mathrm{a}$ ): The Bidder's organs were surrounded by follicles, suggesting the possible development of eggs. The testes were not yet fully ripened. Seminiferous tubules were developing and melanin granules were densely distributed among them. Seminiferous tubules were mostly filled with spermatogonia, but fairly large numbers of first spermatocytes were also seen. In another individual, a few spermatids were seen. A control female, jap. $ᄋ \times j a p$. of (Fig. $2 \mathrm{~b}$ ): Both the Bidder's organs and the ovaries were normally developing. A matured hybrid male, jap. $+\times$ miy. $\hat{o}$ (Fig. $2 c$ ) : The Bidder's organs were normally developed. Fairly large numbers of sperm were seen, indicating rather active sperm formation. A hybrid female jap. 우 $\times$ miy. o (Fig. 2d): The connective tissue was developing in the Bidder's organ and the eggs were slightly degeneratiing. The ovaries were normal and were developing in the same degree as those in the control females. A hybrid male, jap. 우 $\times s p i$. ô (Fig. 2e): The poor state of preservation prevented close examinations. The Bidder's organs were normally developing, while the condition of the testes were slightly different from that of the control males. The testes were not yet ripened. Seminiferous tubules were rather thin. A few abnormal spermatogonia were observed. A hybrid female, jap. o $\times s p i$. o (Fig. $2 \mathrm{f}$ ): The Bidder's organs were mostly filled with connective tissue, and the eggs were degenerating. There were abundant follicle cells where debris of degenerated eggs was absorbed. Few normally developing eggs were observed in the ovaries, which suggested the degeneration and absorption of the eggs after they had partly developed. The tissues near the outer margins of the ovaries were similar to the cortex tissue seen in the immatured ovaries. The conditions found in the Bidder's organs and the ovaries of this hybrid were 


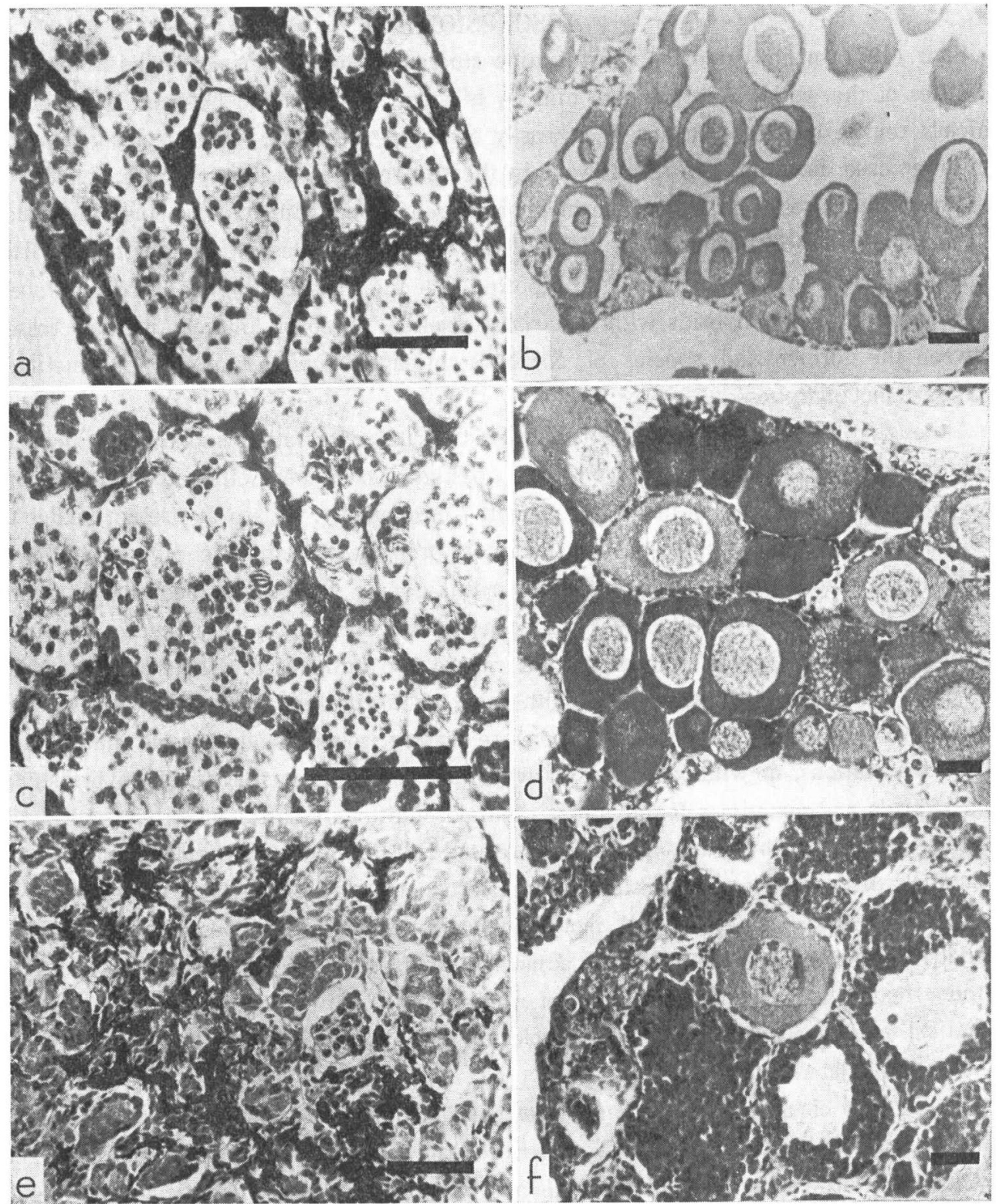

Fig. 2. Cross sections of testes (a, c, e) and ovaries (b, d, f). The black lines are scales denoting $50 \mu$. a, b. Controls, japonicus o $\times$ japonicus ô; c, d. Hybrids, japonicus 우 $\times$ miyakonis $\hat{o}$; e, f. Hybrids, japonicus 우 $\times$ spinosus $\delta$.

identical with those generally observed in the early and middle stages of amphibian sex reversion from female to male. Since no testicular structures were seen in these ovaries, it was impossible to say whether they would change into testes or not. Even so, that the ovarian structures were completely destroyed was quite evident. 


\section{DISCUSSION}

Blair (1972) made extensive hybridization studies on toad species collected from many localities of the world. According to him, $F_{1}$ is sometimes obtained between two geographically remote species. Further, $F_{1}$ is easily obtained within the same species group. In the latter case, however, the results vary in the two reciprocals. For example, females of the americanus group easily produce metamorphosed young with other species, but males of the same group rarely produce viable hybrids with females of other species. Blair went so far as Eurasian Bufo, and he reported that the male $B$. bufo he used produced a few metamorphosed hybrids with $B$. viridıs females. Moreover, intercontinental crosses between the former and species of North American $B$. americanus group sometimes produced metamorphosed $\mathrm{F}_{1}$.

Although Blair's description is extensive, his results were rather superficial, especially when he treated Eurasian species. Further, no studies on genera other than Bufo, com parable to his report, are available at present. Consequently, we are at present unable to generalize the genetic features of $B u f o$, but it is probable that genetic differentiation is preceeded by morphological differentiation in this genus. There have been lots of arguments on the utility of genetical results when we carry on systematic studies of some group of animals. Generally speaking, we regard two forms as the same species when they actually or potentially interbreed with each other with fertile offspring. But we may regard two forms as distinct species when pre-mating isolating mechanisms inhibit natural hybridizations, notwithstanding the availability of experimental fertile hybrids. In fact, hybrids are sometimes found under natural conditions (Blair, 1941), but such cases are not unlimited. There are many closely related and taxonomically problematical species of animals distributed in the western and eastern parts of the Eurasian Continent, i. e. Europe and Asia. Besides, several morphologically related forms of animals are found allopatrically on the continent and its adjacent islands, such as Japan and Formosa. One author treats the taxonomic position of these forms quite differently from another. Genetical evidence may play a great role in clarifing taxonomic problems on these superficially related forms.

In the case of anurans, Kawamura's extensive studies (Kawamura and Kobayashi, 1960; Kawamura, 1962) revealed that the European common frog, Rana temporaria, and the Japanese brown frogs, $R$. chensinensis and $R$. ornatıventris are genetically completely isolated in spite of their close morphological similarities. Similarly, Daito (1968) showed that the European and the Japanese tree frogs (Hyla sarda and H. japonica) are not in a subspecific relation as formerly considered, but are distinct species on the basis of $F_{1}$ sterility. When two faunal groups, distributed between Japan and continental Asia or between Asia and Europe, are considered, the above examples of the genera of anurans other than Bufo seem to suggest that genetical isolation may be proceeding between continental and Japanese common toads. Up to the present, about 20 taxa are known in 
the $B$. bufo species group, including both currently accepted subspecies and morphologically related species, and their taxonomic status and phylogenetic relations are still poorly understood. Actually, the present situation is almost same as at the beginning of this century when Boulenger (1883) dealt badly with the Japanese common toads and Stejneger (1907) put the taxonomic problems on this group in order. B. b. japonicus is distributed in the western half of Japan, and $B . b$. miyakonis in the Miyako Is. of the Ryukyu Archipelago. The latter is now introduced on Minami- and Kita-Daito Is. of the same Archipelago (Matsui, 1975b), but many problems are involved in its origin and taxonomic position. Many workers consider it identical with the Chinese subspecies, B. b. gargarizans (Inger, 1947; Nakamura and Uéno, 1963), but I am of the opinion that there are clear morphological differences between these two forms (Matsui, 1974b). B. b. spinosus is distributed in the mediterranean part of Europe, Asia Minor and Northern-west Africa, and is considered to be a geologically older subspecies than B. b. bufo (Nikol'ski, 1918; Ternt'ev and Chernov, 1949). Some authors consider these two forms not clearly seperated morphologically (De Lange, 1972), but I consider them as two separate subspecies because they are different in their breeding habits (Hotz, 1970). The three subspecies treated in this article are discriminated from each other notwithstanding their great intrasubspecific morphological variations. As the results of crossing experiments, japonicus 우 and miyakonis $\hat{o}$ showed close genetic compatibility, while japonicus 우 $\times$ spinosus $\hat{\delta}$ produced sterile $F_{1}$. As mentioned previously, the results might differ in the reciprocal, but it is conceivable that at least in spinosus and japonicus, genetical isolation is somewhat advanced. Further, in the case of miyakonis, the result of a reciprocal cross might be different from that obtained in the present work, since the morphological characters of this subspecies resemble spinosus rather than japonicus. And even if fertile $F_{1}$ is obtained in the both reciprocals, the existence of premating isolating mechanisms must be examined. B. b. japonicus and B. b. spinosus are the two extreme forms of the common toad, distributed in the peripheral regions of the ranges covered by this species group. Consequently, geographically intermediate forms, such as $B . b$. bufo of northern Europe, should be investigated in future studies, but the results shown in this paper strongly suggested that $B . b$. japonicus may be separated as a full species from $B . b$. spinosus.

\section{ACKNOWLEDGMENTS}

I am greatly indebted to Prof. Louis-Philippe KnOEPfFler of the University of Paris for the supply of French spinosus specimens. Breeding males of miyakonis were offered by Dr. Takuya ABE of the Ryukyu University, to whom the author's hearty thanks are due. Dr. Hisaaki IwASAwa and Mr. Yôsuke Tojyo of the Niigata University kindly examined the gonad sections and gave the author important suggestions, for which he is very grateful. Messrs. Tsutomu Hikida and Masanao Tôyama of Kyoto University assisted the author in rearing tadpoles and it is his pleasure to acknowledge gratitude 
to them.

\section{LITERATURE}

Blair, A. P. 1941. Genetics. 26 : 398-417.

. 1955. Amer. Mus. Novit. 1722 :1-38.

Blair, W. F. 1972. [ed.] Evolution in the genus Bufo. Univ. Texas Press, Austin, 459p.

Boulenger, G. A. 1883. Proc. Zool. Soc. London. $1883: 139-140$.

Daito, Y. 1968. Zool. Mag. 77 :117-127.

De Lange, L. 1973. Beaufortia. 21 : 99-116.

Hotz, H. 1970. Vierteljahrsschr. Naturf. Ges. Zurich. 115 :239-254.

Inger, R. F. 1947. Fieldiana :Zool. 32 : 295-352.

Kawamura, T. 1942. Jap. J. Genetics. $18: 135-138$.

- 1962. J. Sci. Hiroshima Univ. (B-1) 20 : 181-193.

and M. Kobayashi. 1960. Ibid. $18: 221-238$.

Kuramoto, M. 1967. Bull. Fukuoka Univ. Educ. 17 : 103-110. 1974. Copeia. 1974 : 815-822.

Limbaugh, B. A. and E. P. Voipe. 1957. Amer. Mus. Novit. $1842: 1-32$.

Matsui, M. 1974a. Zocl. Mag. 83 :91-95.

1974b. Jap. J. Herp. 5 : 68.

- 1975a. Zool. Mag. 84 :196-204.

. 1975b. Jap. J. Herp. 6 : 43-47.

1976. Contr. Biol. Lab. Kyoto Univ. $25: 1-9$.

Moriya, K. 1951. J. Sci. Hiroshima Univ. (B-1) 12 : 47-56. 1960. Ibid. $18: 125-156$.

Nakamura, K. and S. Uéno. 1963. Japanese Amphibians and Reptiles in Color. Hoikusha, Osaka, 214p.

Nikol'skii, A. M. 1918. Fauna of Russia and Adjacent Countries. (translated by IPST, Jerusalem 1962) 225p.

Rugh, R. 1934. Biol. Bull. 66 :22-29.

Stejneger, L. 1907. Bull. U. S. N. M. 58 :1-577.

Terent'ev, P. V. and S. A. Chernov. 1949. Key to Amphibians and Reptiles. (translated by IPST, Jerusalem 1965) 315p.

Volpe, E. P. 1956. Tulane Stud. Zool. 4 :61-75. 